\title{
Generalization of tooltips: An assistive technology extension
}

\author{
Saira-Banu Adams, William D. Tucker and Isabella M. Venter
}

\begin{abstract}
.
Software applications use tooltips to assist users to improve their understanding of icons. When hovering over an icon with the cursor, a short text description of the icon appears. Textbased tooltips are helpful for users without any literacy limitations. An extension was created to generalize tooltips for users with low text literacy. In this case study and to explore such generalization, video based tooltips show short South African Sign Language clips to assist those who use South African Sign Language as a first language. When the user hovers over an icon, a video appears with a short description of the icon in South African Sign Language. As a way to abstract tooltips, audio-based tooltips have also been developed, for users with language barriers, reading disabilities and those who are visually impaired. When hovering over an icon, a short audio description of the icon plays. Both audio and South African Sign Language video based tooltips have been pre-recorded. Through a web extension, users are able to select a tooltip preference for their Mozilla Firefox Browser for audio-based or video-based tooltips.
\end{abstract}

\section{Introduction}

Most software packages use icons, small visual representations, to represent tools and specific functions located in a toolbar. These icons make the user interface more attractive although the meaning of the icons is not always apparent. Since icons are pictorial rather than text-based, it means that users who understand their meaning can recognize them quickly. The problem arises where multiple icons are needed to represent different functions within a software application, making it challenging for designers to develop easily recognizable icons that represent functionality that may or may not be known to users. To assist users, a user can hover the cursor controlled by the mouse, over an icon, and the meaning of the icon is displayed as a text message. This message disappears immediately once the cursor is moved off the icon [2]. The text message displayed is called a 'tooltip' or 'infotip'. Tooltips provide additional information about an icon or button without crowding the display with too much information, therefore making the interface uncluttered yet helpful to the user [2]. Since tooltips are text-based, they do not benefit all users, especially those who cannot read or understand the tooltip. The size of the tooltip text can also pose a problem for visually challenged users. Tooltips can be made more accessible if users have the option to: select the language they prefer; change the size of the tooltip text; receive the text as a video- or audio-message. It was decided to develop video tooltips to 
assist the Deaf ${ }^{1}$ Community of Cape Town (DCCT) and to enhance their ability to access the Internet. DCCT is a non-governmental welfare organization with the aim to address the needs of Deaf people in the Western Cape. The organization has an active Deaf membership of 1090 members [3]. Projects undertaken by DCCT are mostly intended to develop and empower Deaf people. DCCT has a computer laboratory on their premises which provides the community with access to Information Technology (IT). A certified computer literacy training course called the International Computer Drivers' License (ICDL) is offered to the community in sign language. Besides the IT program, DCCT also offers a variety of other programs with the aim of growing the skills of the Deaf community. South African Sign Language (SASL) is their preferred language [3]. Contrary to popular belief, sign language is not a single language; there exist many variants of sign language and in some cases, such as South Africa, multiple variants can be found in a single region. To assist this community, tooltips needed to be designed in the more widely understood version of SASL.

Internet browsing is a popular activity used daily by many DCCT members. The Mozilla Firefox browser was thus the software package chosen to be extended with assistive, video and audio-based, tooltips. This browser is open source and easy to use; users do not have to be very technically literate to use it.

To ensure that the design of the tooltips met with the needs of the proposed users, participatory design was chosen as the research methodology as it involves the users in the design of an artefact. Data was collected using both qualitative and quantitative methods. The tooltip extensions designed for Mozilla Firefox were tested by a few Deaf participants at DCCT as well as some software experts and was found to be very useful.

\section{Literature Review}

In a paper by Petrie, Weimann \& Weber, visual and video tooltips were created-based on the icons of Microsoft Foundation Classes Toolbar-to assist Deaf people with the understanding of icons [8]. Their solution consists of four tooltips: a sign language video, an enlarged icon with a text description, digital lips and human mouthing clearly speaking the function out for lip reading. These tooltips were tested by a group of deaf users. The sign language video (a) and picture tooltips (d) were rated to be the most beneficial (see Fig. 1)

WordPress developed a plugin called WordPress tooltip. Their tooltip solution is aimed at helping bloggers post tooltips within blog posts and consists of text, images, links, video, radio or mp4 formats. It can also be used as glossary. The WordPress tooltip provides bloggers with the ability to add related information to their blogs and gives the reader access to this additional information when hovering over text, images or a link [11]. 


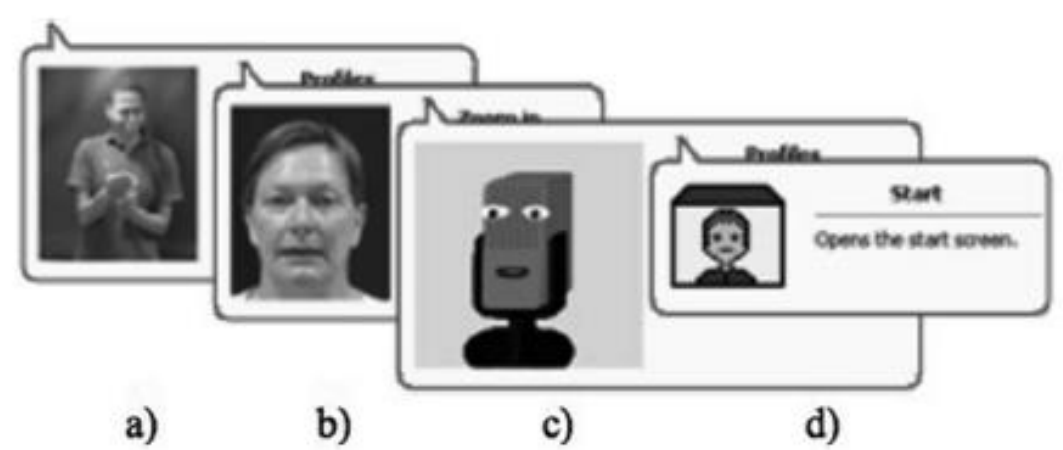

Fig. 1. Augmented Tooltips (a) sign language video, (b) human mouthing, (c) digital lips, (d) enlarged icon with a text description (Petrie, Weimann \& Weber). [8]: Page 1132

The Mac operating system (macOS) implemented an accessibility feature called VoiceOver for Blind users. Blind students have found VoiceOver to be beneficial as their notes can be read aloud to them [7]. Audio tooltips, using touch sensors, can assist visually impaired users to select the correct controls when using devices. When the user lightly touches a control with a finger, an audio tooltip plays, describing the function of the control [7].

The extensive use of text within most computer software is problematic for Deaf people since most are functionally illiterate. This especially becomes an issue when the Deaf have to access services such as travel information or banking, which now almost always require the ability to use information technology. There is a need for more computer software to be available for Deaf people in their first language, namely, sign language [1]. In a study by Ahmad, he mentions the difficulty of determining user requirements for Deaf people since an interpreter needs to be present. When information about user requirements, is collected, it is challenging, but necessary, to get this information as accurate and complete as possible since the information is not received from the Deaf person themselves but from an interpreter [1]. This situation may skew the information.

A software solution called the Automatic Translation into sign Languages (ATLAS) project was a project developed with the purpose of enhancing Deaf people's access to the services and content provided by IT [10]. The system developed consists of an automatic sentence translator from Italian text to Italian Sign Language (LIS). The domain of this software is a weather forecast system where LIS translations are signed by a virtual character animation, which uses pre-captured hand animated signs [9].

\section{Methods and Materials}

To address the question as to whether assistive tooltips would make software more accessible for Deaf users, it was decided to include Deaf participants in the design of the tooltip technology. Participatory design is a methodology that involves stakeholders in the design process in order to ensure that the end product meets the needs of the intended users [6]. 
Evolutionary cooperative prototyping was thus used to design the prototype since this approach allows "enhanced communication with end-users, improved incorporation of end-user insights into the prototypes, and stronger collective ownership and collective action-planning by the team" [6]. The assistive tooltip extension to the browser software was co-designed with participants at DCCT.

The participative design of the tooltip was executed ethically based on Lund's five principles for ethical research [4]: 1. To minimize the risk of harm, the participants were regular users of the equipment in the IT laboratory and thus knew the environment; 2. Informed consent was obtained from each participant; 3 . The participants were informed that their responses would be anonymous and the data collected would be confidential; that is, it would only be used by the researcher and would be destroyed once the research had been completed; 4. The researcher took care to avoid deceptive practices; and finally, 5. The participants were given the right to withdraw [4]. Ethical permission for this research was received from the university's ethical committee (number 15/7/232). Participatory Design is a methodology executed in three phases, (see Fig. 2).

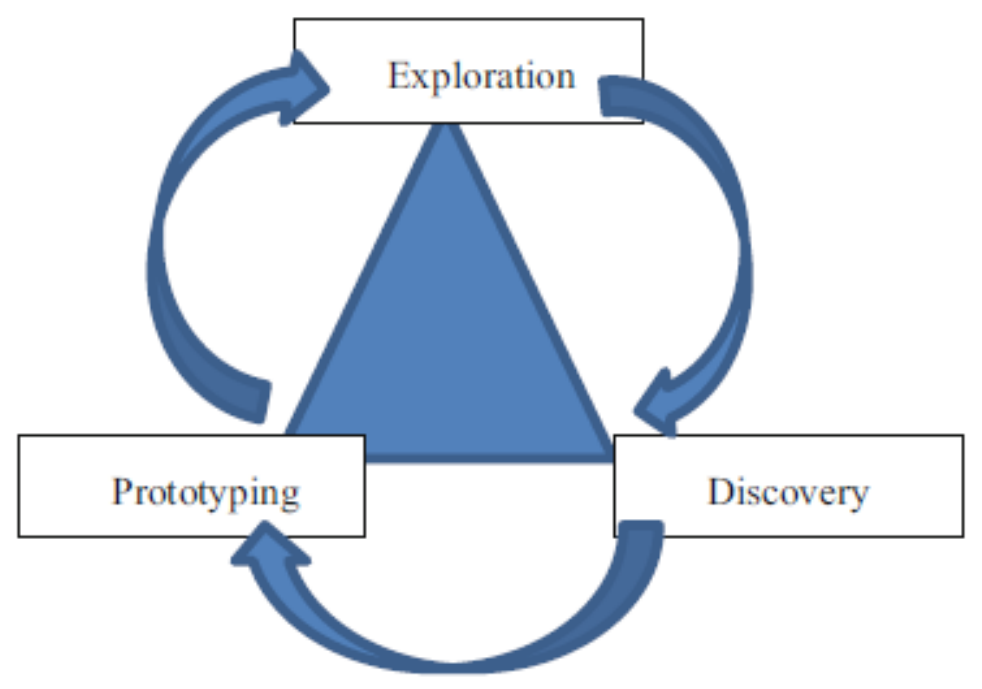

Fig. 2. Participatory design process

\subsection{Phase 1: Initial Exploration of Work}

During the first stage of this participatory design, the designer met with the users and discussed the users' workflow and their lives in order to grasp an understanding of who the software would be designed for [6]. A SASL interpreter, who is a child of Deaf adults (CODA), was used to assist with this process. Since a CODA's mother tongue is sign language, their interpretation is more useful than the interpretation of a second language sign language interpreter. To refine the prototype, two CODA interpreters and a DCCT member codesigned the tooltip extension in three iterations. 


\subsection{Phase 2: Discovery Process}

This phase normally entails gathering needs from users. The users' needs and goals were analysed and prioritized, and a desired project outcome was agreed upon [6]. The main goal of the tooltips was to ensure that icons and functions would be easily understood by the users. Since the tooltips consist of many technical terms for which no SASL signs have been developed the CODA interpreter, during the first iteration of the design, created her own signed terminology for the icons. In the second iteration, this was reconsidered and it was decided rather to explain the icons in normal SASL terms using analogies. For example: the tooltip "bookmark this page" was signed in SASL as placing a bookmark in a physical book. During the final iteration, through the different phases, all the tooltips were re-recorded. The design team agreed upon how each tooltip would be signed.

\subsection{Phase 3: Prototyping}

During this stage, a prototype artefact was created to meet the needs of the user and to meet the desired outcome [6]. Using Hypertext Mark-up Language (HTML), Cascading Style Sheets (CSS) and Java Scripting, a prototype for the assistive tooltip extension to the Mozilla Firefox browser was written (see Fig. 3).

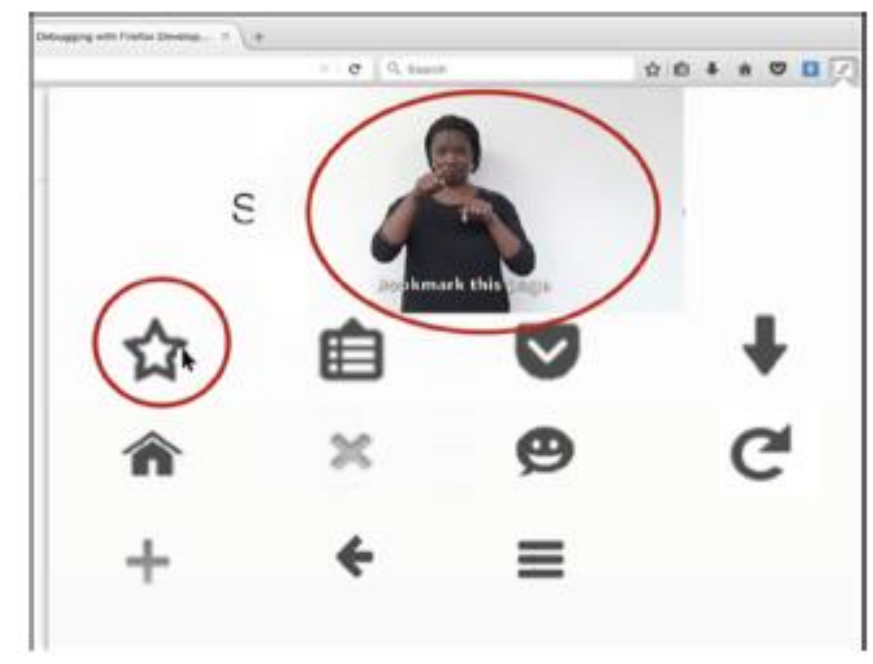

Fig. 3. Assistive SASL video tooltip for Mozilla Firefox browser.

This extension allowed either a video clip or an audio clip to be played when the cursor was moved over the icon (mouse-over). Tooltips for eleven standard browser icons were developed for Mozilla Firefox. SASL videos and audio clips were recorded and placed within the extension for each corresponding icon. Interviews were conducted with the participants after this intervention.

To confirm that the prototype was usable and correct, content verification and usability evaluations were done, in the next section the design of the evaluation will be discussed. 


\subsection{Design of the Evaluation}

Deaf and CODA participants (5) checked both content-whether the sign language is signing the correct text translation [5] -and usability. In addition five software experts, randomly chosen, were asked to do a heuristic walkthrough of the software to test the tooltips' usability.

\section{Content}

Computer literate SASL signers, who were acquainted with the Firefox browser, were required to do this testing. Eleven video clips were placed in a folder in a random order, and each video was allocated a random number as a file name.

The participants were given a pre-prepared form with the numbers of the video clips and a space next to each number to record the text, as understood by the participant. They were asked to watch each of the eleven video clips and then write down the text translation of the tooltip on the form. The video clip was marked as correct on the form only when the text translation of the video clip reflected the required translation.

\section{Usability}

To test the usability, the participants were shown how to use the software and the tooltip extension. The participants were then asked to interact with the software and to fill in a usability testing survey. The survey consisted of questions to provide usability feedback based on the participants experience using the extension. While the participants were testing the software, the researcher observed them.

\section{Heuristic Walkthrough}

To further test the usability of the software a heuristic walkthrough by five software experts was done, which according to Preece et al. [9], can identify approximately $75 \%$ of usability problems (see Fig. 4). A heuristic walkthrough is an informal testing method using a set of heuristics to evaluate an artefact. The experts were asked to evaluate the tooltip software in terms of the following usability principles:

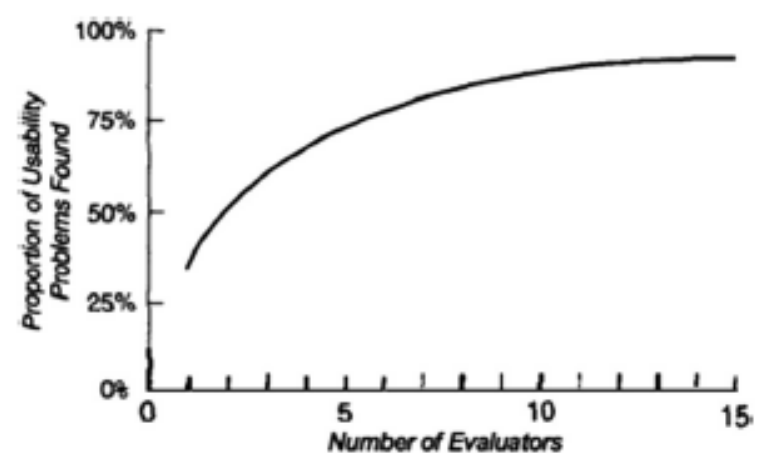

Fig. 4. The curve depicts the ratio of problems within an interface identified by a heuristic evaluation using a range of numbers of evaluators (Preece et al.). [9]. Page 409 
- Feedback: feedback about an action.

- Match between the system and the real world: icons resemble the action that they represent.

- Recognition rather than recall: all options and actions are easily visible

- Aesthetic and minimalist design: simple dialogs do not contain any irrelevant information.

- Flexibility and efficiency of use: software caters for experienced and inexperienced users.

\section{Results}

\subsection{Testing by SASL Participants}

\section{Content Verification Results}

Nine out of the eleven tooltip video clips' were translated correctly by the participants, only video clips 4, 8 and 10 were unclear (see Table 1) since none of the three participants could interpret these tooltips correctly. Although the text translations of Participants 2 and 3 for Videos 1 and 2 are not the exact text translation of the tooltips, the participants' translations were still reasonable descriptions of the functions of the icons. The Deaf participants gave suggestions as to how these unclear videos, could be signed correctly. These videos were then re-interpreted and re-recorded.

\section{Usability Testing}

The aim of usability testing was to determine how the users interact with the software; whether the extension developed is user friendly; how easy the software is to use; how easy it is to learn to use the software and how easy it is to navigate the user interface of the software. The testing procedure was explained, the software solution demonstrated to the participants using a tooltip information sheet, and a consent form was signed.

To evaluate the usability of the extension, each participant was handed a pre-designed questionnaire to complete while testing the software. The participants interacted with the software and completed the questionnaire. On analysis of the data the following was found: User-friendliness. All participants agreed that to make the system more user-friendly, the video tooltip should loop on mouse-over, instead of only playing once. During the concluding interview, a Deaf participant noted that she had always seen the buttons in her browser's toolbar but had never used them because she did not know their functions.

Ease of use. Although participants said that the subtitles on the video clip were clear and easy to read, they felt that subtitles were unnecessary since they only viewed the SASL tooltip. One participant suggested that there should be an option to add subtitles or not. The participants also suggested that the video clips be signed by a native Deaf signer rather than by an interpreter. They felt that then it would be easier for Deaf people to understand.

Learnability. Overall all participants found the software easy to learn. Since many of the tooltip terms are technical, the participants suggested that the tooltip for each button should be described and explained (rather than spelled out) in the video clip.

Ease of navigation. All participants said that the position of the video tooltip was easy to find and should not be placed anywhere else. All participants felt that navigation between pages was easy. 
Table 1. Content verification results

\begin{tabular}{|c|c|c|c|c|c|c|}
\hline Tip & $\begin{array}{l}\text { Tooltip } \\
\text { meaning }\end{array}$ & Participants 1 & 2 & 3 & 4 & 5 \\
\hline 1 & $\begin{array}{l}\text { Bookmark this } \\
\text { page }\end{array}$ & $\begin{array}{l}\text { Bookmark this } \\
\text { page }\end{array}$ & $\begin{array}{l}\text { Choose } \\
\text { bookmark }\end{array}$ & $\begin{array}{l}\text { Choose } \\
\text { book-mark } \\
\text { from this page }\end{array}$ & $\begin{array}{l}\text { Choose } \\
\text { Bookmark }\end{array}$ & $\begin{array}{l}\text { Select to } \\
\text { bookmark } \\
\text { the page }\end{array}$ \\
\hline 2 & $\begin{array}{l}\text { Show your } \\
\text { bookmarks }\end{array}$ & $\begin{array}{l}\text { Show your } \\
\text { bookmarks }\end{array}$ & Bookmarks & $\begin{array}{l}\text { This icon } \\
\text { shows you the } \\
\text { bookmarks }\end{array}$ & $\begin{array}{l}\text { Show your } \\
\text { Bookmarks }\end{array}$ & $\begin{array}{l}\text { Show the } \\
\text { bookmarks }\end{array}$ \\
\hline 3 & Save to pocket & Save to pocket & $\begin{array}{l}\text { Pocket } \\
\text { save }\end{array}$ & $\begin{array}{l}\text { This icon is } \\
\text { saved pocket } \\
\text { save }\end{array}$ & $\begin{array}{l}\text { Save to } \\
\text { pocket }\end{array}$ & $\begin{array}{l}\text { Use this } \\
\text { icon to save } \\
\text { to pocket }\end{array}$ \\
\hline 4 & $\begin{array}{l}\text { Display the } \\
\text { progress of } \\
\text { ongoing } \\
\text { downloads }\end{array}$ & $\begin{array}{l}\text { Display the } \\
\text { progress of } \\
\text { ongoing } \\
\text { downloads }\end{array}$ & $\begin{array}{l}\text { Scroll } \\
\text { down }\end{array}$ & $\begin{array}{l}\text { Icon is used to } \\
\text { download }\end{array}$ & $\begin{array}{l}\text { Use icon to } \\
\text { download }\end{array}$ & Scroll down \\
\hline 5 & $\begin{array}{l}\text { Mozilla } \\
\text { Firefox } \\
\text { startpage }\end{array}$ & $\begin{array}{l}\text { Mozilla } \\
\text { Firefox } \\
\text { startpage }\end{array}$ & $\begin{array}{l}\text { Mozilla } \\
\text { homepage }\end{array}$ & $\begin{array}{l}\text { Opens Mozilla } \\
\text { homepage }\end{array}$ & $\begin{array}{l}\text { Mozilla } \\
\text { homepage }\end{array}$ & $\begin{array}{l}\text { House icon } \\
\text { means } \\
\text { Mozilla } \\
\text { homepage }\end{array}$ \\
\hline 6 & $\begin{array}{l}\text { Start a } \\
\text { conversation }\end{array}$ & $\begin{array}{l}\text { Start a } \\
\text { conversation }\end{array}$ & $\begin{array}{l}\text { Icon to } \\
\text { start a chat }\end{array}$ & $\begin{array}{l}\text { Smile is to start } \\
\text { a conversation }\end{array}$ & $\begin{array}{l}\text { Smile icon } \\
\text { is to start a } \\
\text { chat }\end{array}$ & $\begin{array}{l}\text { Smile icon } \\
\text { means talk }\end{array}$ \\
\hline 7 & Open menu & Open menu & $\begin{array}{l}\text { Press to } \\
\text { open menu }\end{array}$ & $\begin{array}{l}\text { This is open } \\
\text { your menu }\end{array}$ & Menu page & $\begin{array}{l}\text { Press to } \\
\text { open menu }\end{array}$ \\
\hline 8 & $\begin{array}{l}\text { Go back one } \\
\text { page, pull } \\
\text { down to show } \\
\text { history }\end{array}$ & $\begin{array}{l}\text { Go back one } \\
\text { page, pull } \\
\text { down to show } \\
\text { history }\end{array}$ & $\begin{array}{l}\text { Open } \\
\text { again, } \\
\text { show } \\
\text { history }\end{array}$ & $\begin{array}{l}\text { You can go } \\
\text { back to what } \\
\text { you previously } \\
\text { opened }\end{array}$ & $\begin{array}{l}\text { Go back to } \\
\text { recent }\end{array}$ & $\begin{array}{l}\text { Open to } \\
\text { show } \\
\text { history }\end{array}$ \\
\hline 9 & Close tab & Close tab & $\begin{array}{l}\text { Press } \\
\text { button to } \\
\text { close }\end{array}$ & Close this tab & Close tab & Close tab \\
\hline 10 & Open new tab & Open new tab & $\begin{array}{l}\text { Tabs name } \\
\text { is open }\end{array}$ & $\begin{array}{l}\text { This is the open } \\
\text { tab button }\end{array}$ & Open a tab & $\begin{array}{l}\text { Open new } \\
\text { tab }\end{array}$ \\
\hline 11 & $\begin{array}{l}\text { Reload current } \\
\text { page }\end{array}$ & $\begin{array}{l}\text { Reload current } \\
\text { page }\end{array}$ & $\begin{array}{l}\text { Loading } \\
\text { page again }\end{array}$ & $\begin{array}{l}\text { Opens the same } \\
\text { page again }\end{array}$ & $\begin{array}{l}\text { Reload } \\
\text { page }\end{array}$ & $\begin{array}{l}\text { Loading } \\
\text { same page } \\
\text { again }\end{array}$ \\
\hline
\end{tabular}

\subsection{Heuristic Walkthrough Results}

The software experts were asked to evaluate the tooltip software in terms of specific usability principles: 
Feedback. The experts strongly agreed that the user is always aware of what functions they may perform within the extension. Furthermore, they agreed that every video clip appears without any lag on mouse-over.

Match between the system and the real world. The experts strongly agreed that the buttons/icons were easily recognizable and could be related to real world situations. For example, the icon with the house meant "go home" and the cross button meant "close tab". Recognition rather than recall. Since the icons resembled the functions they were easily recognizable.

Aesthetic and minimalist design. All experts strongly agreed that the layout of the extension was straight forward and the explanations did not contain any unnecessary information. Three experts suggested that the subtitle colour should be changed to yellow rather than white to make it easier for the user to see.

Flexibility and efficiency of use. All experts agreed that they were always aware of where they were, what they could do and where they could go within the extension.

\section{Conclusion}

The tooltips provided by most software packages are text-based and explain the functionality of buttons or icons with a mouse over. These text explanations are in most cases not useful for Deaf users as many are "textually" illiterate. In order to make assistive tooltips more accessible for Deaf users, it was decided to include Deaf participants from a Deaf community in Cape Town in the design of the tooltip technology and to create SASL video tooltips for the Mozilla Firefox browser. These tooltips were then tested with the Deaf users of DCCT.

It was found that DCCT users preferred the video tooltips. They felt that the text subtitles that were added to videos for further information were superfluous, as they did not read them. In their experiments, Petrie et al. [8] also found that Sign Language tooltips were of more benefit to Deaf computer users than text.

It became evident that there are no SASL signs for technical terms. It was therefore necessary to explain these terms in detail rather than spell them out. It would be useful if SASL translations of technical terms could be developed. These will simplify the video recorded explanations. If assistive tooltips for more applications can be developed, especially for Deaf computer users, these users will learn the meaning of technical terms. Over time this will allow Deaf users to improve their understanding of, and become familiar with, the technical requirements of software. The participants at DCCT positively experienced video tooltips.

There is definitely a need for more assistive technologies for a range of dis abled people. It is clear that without assistive technologies, the Deaf computer users were limited in their use of the features offered on most software applications. Assistive technologies, such as tooltips, will allow them to explore new software applications and it will make the software more user-friendly for Deaf users. Without assistive tooltips these users are unaware of how many features of the software exist and how they function. This became evident from the participants' comments that they were previously ignoring buttons or icons that were 
present in the Mozilla Firefox browser just because they did not know what the buttons or icons meant or how they functioned.

\section{Future Work}

Based on our experience with video tooltips for Deaf users, we can safely assume that other types of low literacy end users could benefit from this approach. In order to improve and expand on the assistive tooltips, and to make them more accessible to a range of users, the following can be considered:

- Assistive tooltips can be adapted to be used with different browsers;

- An authoring tool for creating tooltips can be developed with a drag and drop tool where the audios or videos of choice could just be dragged and dropped on the correct icon.

- Where video clips were not correctly understood, the participants suggested how they felt the videos could be signed so that the meaning would be made clearer. These suggestions will be incorporated in the next prototype design and the tooltips will be rerecorded.

\section{References}


1. Ahmad, N.: People Centered HMI's for Deaf and Functionally Illiterate Users (2014)

2. Cassezza: Patent No. 9,501,178. Washington, D.C. (2016)

3. DCCT Welcome to Deaf Community of Cape Town-DCCT. http://www.DCCT.org.za. Accessed o8 Mar 2017

4. Lærd Dissertation Principles of research ethics.

http://dissertation.laerd.com/principles-of-research-ethics.php Accessed 23 Mar 2017

5. Mothlabi, M.: Usability and content verification of a mobile tool to help the deaf person with pharmaceutical instruction (2014)

6. Muller, M.: Participatory design: the third space in HCI. In: Human Computer Interaction: Development Process, pp. 165-185 (2003)

7. O'Connell, T., Freed, G., Rothberg, M.: Using Apple technology to support learning for students with sensory and learning disabilities, pp. 19-21. WGBH Educational Foundation (2010)

8. Petrie, H., Fischer, W., Weimann, K., Weber, G.: Augmenting icons for deaf computer users. In: Extended abstracts on Human Factors in Computing Systems, pp. 1131-1134 (2004)

9. Preece, J., Rogers, Y., Sharp, H.: Interaction Design: Beyond Human-Computer Interaction. Wiley, Chichester (2015)

10. Vendrame, M., Tiotto, G.: ATLAS project: forecast in Italian sign language and annotation of corpora. In: Proceedings of 4th Workshop on the Representation and Processing of Sign Languages: Corpora and Sign Language Technologies, Valetta, pp. 22-23 (2010)

11. Wordress Tooltips Plugin - Tooltips Pro. http://www.tooltips.org/features-ofwordpress-ttooltips-plugin/ooltips-plugin/. Accessed o3 July 2017 